\title{
Management of Stress Urinary Incontinence in Females with Diabetic Mellitus (Type 2)
}

Marzieh Kargar Jahromi*, Somayeh Ramezanli, Leila Taheri and Afifeh Rahmanian

Jahrom University of Medical Science, Jahrom, Iran

\begin{abstract}
Background and objectives: Stress urinary incontinence is involuntary loss of urine with sneezing, coughing and effort and is a frequent and bothersome symptom that is common in the elderly population. The aim of the present study was to determine the effect of Pelvic floor muscle exercises and bladder training on quality of life of the diabetic elderly females with stress urinary incontinence in jahrom city (Shiraz), Iran, 2013.

Material and methods: The study was conducted from May to September, 2013 at the 3 health centers in Jahrom city. The instruments used for the study were the Questionnaire for urinary incontinence diagnoses (QUID) and Incontinence Quality of life Questionnaire (I-QOL). Quid questionnaire was used for choosing the type of incontinence in the elderly females. After an explanation of the aim of the study by the researcher, 60 participants with all the required criteria and stress score $\geq 4$ were selected as the study sample for the intervention. Participants divided into experimental and control groups, and completed I-QOL questionnaire before the intervention, immediately, 2 and 3 months after the last session of training. Descriptive statistics, paired t-test and repeated measurement were used to analyze the data.
\end{abstract}

Results: It is shown that immediately, 2 and 3 months after the intervention, I-QOL subtype scores had a significant difference between the two groups. In other words, the training sessions improved the score of I-QOL in the intervention group $(P<0.0001)$ versus control group $(P=0.6)$.

Conclusion: The Behavioral Intervention Program significantly improved the quality of life outcomes of the diabetic elderly females with stress urinary incontinence. Thus, it is concluded that the diabetic individuals with incontinence can be significantly improved following instruction by health care providers.

Keywords: Stress urinary incontinency; Diabetic mellitus; Elderly; Management

\section{Introduction}

Urological symptoms are receiving increasing recognition as a major public health problem [1]. Urologic issues are the third most common type of complaint in patients 65 year of age or older and account for at least a part of $47 \%$ of office visits [2].

Urinary incontinence (UI) is defined as the "involuntary loss of urine that is objectively demonstrable [3]. Stress incontinence (SI) is involuntary loss of urine with sneezing, coughing and effort and is a frequent and bothersome symptom that is common in the elderly population [4].

Urinary incontinence has high prevalence in older women with diabetes mellitus [5]. The prevalence of UI in older women is approximately 2 times that of older men [6]. In women over the age of 60 , the estimated prevalence of urinary incontinence ranges from $17 \%$ to $49 \%$ [7].

Despite the high estimate of prevalence, as many as $50 \%$ of all cases of UI may not have been reported, because individuals with UI do not always seek medical help [8]. Feel embarrassed [9] and there is a misconception that the conditions cannot be treated [10]. Particularly in older females the fear of surgery is a further concern to patients [11].

In previous studies, urological symptoms have been associated with a detrimental effect on well-being [12]. Females with urinary incontinence have a lower quality of life (QoL) [13]. People with UI report restrictions on physical activity, stress, frustration, thoughts of suicide, confusion, depression, anger, less well-being, low self-esteem, social isolation, and poor sleep [14].

UI affects the physical, psychological, social, and economic wellbeing of individuals and their families and poses a substantial economic burden on health and social services [15].

Current treatments for UI include behavioral (e.g., bladder training, fluid manipulation, scheduled toileting, pelvic floor muscle exercises [16]. Behavioral techniques are now currently recommended as first-line therapy in the treatment of UI [17]. Behavioral interventions are usually relatively inexpensive and easy to implement, but their effectiveness depends chiefly on patient motivation and compliance [18].

The use of pelvic floor muscle (PFM) exercises in the treatment of stress urinary incontinence is based on two functions of the pelvic floor muscles: support of the pelvic organs, and a contribution to the

*Corresponding author: Marzieh Kargar Jahromi, Comunity Health Nursing, Faculty of Nursing, Jahrom University of Medical Science (of shiraz) Motahari Street, Jahrom (from shiraz), Iran, Tel: 00987913341501; E-mail: ramezanli1362@gmail.com

Received February 03, 2014; Accepted March 04, 2014; Published March 10 2014

Citation: Jahromi MK, Ramezanli S, Taheri L, Rahmanian A (2014) Management of Stress Urinary Incontinence in Females with Diabetic Mellitus (Type 2). J Diabetes Metab 5: 351. doi:10.4172/2155-6156.1000351

Copyright: (c) 2014 Kargar M, et al. This is an open-access article distributed under the terms of the Creative Commons Attribution License, which permits unrestricted use, distribution, and reproduction in any medium, provided the original author and source are credited. 
sphincter closure mechanism of the urethra [19]. A PFM program may be prescribed to increase strength, endurance, and coordination of muscle activity. Strength training decreases the frequency of SUI with time, and skill training immediately reduces the amount of leakage $[20,21]$. Pelvic floor rehabilitation is generally the first-line treatment for female patients with SUI [22].

Bladder training (also called urge suppression or scheduled voiding) is an important first-line strategy. The intent is to increase the voiding interval by consciously suppressing the urge to void; patient education, scheduled voiding, positive reinforcement, and ongoing support are helpful [14].

The aim of the present study was to determine the effect of Pelvic floor muscle exercises and bladder training on quality of life of the diabetic elderly females with stress urinary incontinence.

\section{Methods}

\section{Study design}

This study was an interventional study with simple random sampling to explore the evaluating the effectiveness of Pelvic floor muscle exercises and bladder training in the diabetes elderly females with Stress Urinary Incontinence referring to health centers in Jahrom city (shiraz), Iran, 2013.

\section{Study setting and sample}

The study was conducted from May to September, 2013 at the 3 health centers in Jahrom city. These centers have about 500 registered members aged above 55 . The inclusion criteria were diabetes female adults aged 60-74 years old, who were members of the centers and having Quid score for incontinence type (stress score $\geq 4$ ). Clinical symptoms of urinary incontinence in the last 6 months, and willingness to participate in the study. The exclusion criteria were absence in more than two training sessions, suffering from central nervous system disease (e.g. multiple sclerosis, cerebrovascular accident or acute mental illness and dementia, recent urology surgery (for less than three months), history of genitourinary malignancy, current urinary infection, hysterectomy and diabetes mellitus type 1).

On the basis of these criteria 60 diabetes older adults were selected randomly to participate in the study and asked to sign the informed consent form and fill in the demographic questionnaire.

\section{Data collection}

The instruments used for the study were the Questionnaire for urinary incontinence diagnoses (QUID) and Incontinence Quality of life Questionnaire (I-QOL). Quid questionnaire was used for choosing the type of incontinence in the elderly females. Given the importance of urinary incontinence on quality of life, there is increasing interest in the use of well-constructed questionnaires. Stress and urge urinary incontinence, the most common conditions that cause female urinary incontinence symptoms, has different pathophysiologic mechanisms, epidemiologic characteristics, and treatments. Distinguishing between these types of urinary incontinence is important in clinical practice and for research purposes.

On the basis of previous research and expert clinical opinion, we used a QUID questionnaire to distinguish stress from urge incontinence that includes 6 questions and requires about 5 minute to complete. We believe that this is partly because national guidelines recommend an extended evaluation for classifying type of incontinence that is not practical in health care centers. The QUID questionnaire is a simple, quick, and reproducible test with acceptable accuracy for classifying urge, mix and stress incontinence among women who are appropriate for evaluation and treatment in health care centers.

Internal consistency and test-retest reliability estimates were good. Sensitivity and specificity were $85 \%$ (95\% CI, 75\%, 91\%) and 71\% (95\% CI, 51\%, 87\%), respectively, for stress urinary incontinence and $79 \%$ (95\% CI, 69\%, 86\%) and 79\% (95\% CI, 54\%, 94\%), respectively, for urge urinary incontinence. The Questionnaire for Urinary Incontinence Diagnosis correctly diagnosed urinary incontinence type in $80 \%$ of subjects [23]. Indeed, QUID questionnaire gave us the possibility to determine the types of urinary incontinence. After an explanation of the aim of the study by the researcher, 60 participants with all the required criteria and stress score $\geq 4$ were selected as the study sample for the intervention. Participants divided into experimental and control groups, and completed I-QOL questionnaire before the intervention, immediately, 2 and 3 months after the last session of training. I-QOL questionnaire consisted of 22 item in three dimensions: Avoidance and Limiting Behavior (8 questions), the Psychosocial Impacts (9 questions), and Social Embarrassment (5 questions). All questions have been five options Likert scale from 1 to 5 points.

\section{Intervention}

The experimental group was divided into 2 sub-groups ( 15 in each) and 8 training sessions were held weekly for each subgroup.

A behavioral intervention program was composed of urinary incontinence education, pelvic floor muscle exercise, and bladder training. The contents of the education program included the causes, symptoms, diagnoses, and treatments of stress urinary incontinence, the locations and functions of pelvic floor muscle exercises, methods of pelvic floor muscle exercise and bladder training. The program used in the present study was developed by the authors on the basis of methods employed in previous studies by Dougherty et al. [24] and Lee [25].

The women randomized to the intervention group were trained on a one-to-one basis by the investigator (a trained nurse) over 8 weekly visits.

According to literature review, pelvic floor muscle exercises were applied for mostly $6-12$ weeks, 1 week at the shortest and 12 week at the longest [26].

An instruction booklet was distributed among participants. Finally, the first evaluation was carried out just after the 8 week intervention by filling the I-QOL questionnaire. Also for assessing the effect of selfpractice program, the I-QOL questionnaire was completed by groups after a gap of 2 and 3 months.

\section{Data analysis}

The results were analyzed by SPSS version 16. Analysis was presented with mean and standard deviation. The results were reported by independent $t$-test and repeated measurement.

\section{Results}

In our study $50.6 \%$ of the participants were married, $68.7 \%$ were educated under diploma, $89.6 \%$ had normal vaginal delivery and $71.5 \%$ had given birth to four children or more.

As shown in Table 1, the mean score for I-QOL subtypes before the intervention did not have a significant difference between the two groups. 
The results after the intervention are shown in Tables 2-4. It is shown that immediately, 2 and 3 months after the intervention, I-QOL subtype scores had a significant difference between the two groups. In other words, the training sessions improved the score of I-QOL in the intervention group $(\mathrm{P}<0.0001)$ versus control group $(\mathrm{P}=0.6)$.

\section{Discussion}

Diabetes mellitus (DM) is a worldwide health problem with rising prevalence [27]. DM is a chronic disease, which can lead to important complications like neuropathy, retinopathy, and nephropathy [28]. Recent studies have shown that urinary incontinence (UI) among adult women has also rising prevalence and incidence, especially with higher age [29]. The etiology of UI is not well understood yet, but research mainly suggests that the same mechanisms as in diabetic microvascular complications contribute to it [30]. Stress incontinence is incontinence due to inability of the urethral sphincter to generate enough resistance to retain urine (i.e., it is open when it should be closed) [31].

Epidemiological evidence from several studies has linked these 2 disorders and shown that urinary incontinence is $50 \%$ to $200 \%$ more common in women with type 2 diabetes than in women with normal glucose [32]. For example, in the Nurses' Health Study, a large cohort of women, the prevalence of weekly incontinence was $17 \%$ in those without diabetes and $24 \%$ in those with diabetes [33].

However, despite mounting evidence of a link between diabetes and incontinence, little is known about the mechanisms by which

\begin{tabular}{|l|c|c|c|c|c|}
\hline Time & \multicolumn{4}{|c|}{ Before the Intervention } & P-value \\
\hline Group & \multicolumn{2}{|c|}{ Intervention } & \multicolumn{2}{c|}{ Control } & \\
\hline Variable I-QOL Sub Types & M & SD & M & SD & \\
\hline Avoidance \& Limiting Behavior & 35.98 & 21.89 & 34.23 & 16.75 & 0.2 \\
\hline Psychosocial Impacts & 46.25 & 17.45 & 47.56 & 21.65 & 0.6 \\
\hline Social Embarrassment & 38.12 & 22.20 & 36.35 & 14.61 & 0.5 \\
\hline I-QOL total & 40.11 & 20.51 & 39.38 & 17.67 & 0.4 \\
\hline
\end{tabular}

Table 1: Comparison of mean of I-QOL score subtypes before the intervention in the two groups.

\begin{tabular}{|c|c|c|c|c|c|c|c|}
\hline \multirow{3}{*}{\begin{tabular}{|l|} 
I-QOL Sub Types \\
Time \\
Group
\end{tabular}} & \multicolumn{6}{|c|}{ Avoidance and Limiting Behavior } & \multirow{3}{*}{\begin{tabular}{|c|} 
P-value \\
0.004
\end{tabular}} \\
\hline & \multicolumn{2}{|c|}{ Immediately } & \multicolumn{2}{|c|}{$2 \mathrm{~m}$ later } & \multicolumn{2}{|c|}{$3 \mathrm{~m}$ later } & \\
\hline & M & SD & SD & $\mathrm{M}$ & SD & M & \\
\hline Intervention & 37.14 & 19.36 & 45.04 & 20.75 & 52.33 & 21.82 & \\
\hline Control & 35.23 & 16.75 & 34.93 & 24.25 & 32.3 & 19.38 & \\
\hline
\end{tabular}

Table 2: Comparison of mean of Avoidance and Limiting Behavior score after the intervention in the two groups.

\begin{tabular}{|c|c|c|c|c|c|c|c|}
\hline \multirow{3}{*}{\begin{tabular}{|l|} 
I-QOL Sub Types \\
Time \\
Group
\end{tabular}} & \multicolumn{6}{|c|}{ Psychosocial Impacts } & \multirow{3}{*}{$\begin{array}{c}\text { P-value } \\
0.05\end{array}$} \\
\hline & \multicolumn{2}{|c|}{ Immediately } & \multicolumn{2}{|c|}{$2 \mathrm{~m}$ later } & \multicolumn{2}{|c|}{$3 \mathrm{~m}$ later } & \\
\hline & $M$ & SD & $M$ & SD & $M$ & SD & \\
\hline Intervention & 47.34 & 19.35 & 52.02 & 20.81 & 58.42 & 20.79 & \\
\hline Control & 46.45 & 19.52 & 44.75 & 18.10 & 43.65 & 19.75 & \\
\hline
\end{tabular}

Table 3: Comparison of mean of Psychosocial Impacts score after the intervention in the two groups.

\begin{tabular}{|c|c|c|c|c|c|c|c|}
\hline I-QOL Sub Types & \multicolumn{6}{|c|}{ Social Embarrassmen } & \multirow{2}{*}{$\begin{array}{c}\text { P-value } \\
0.04\end{array}$} \\
\hline Time & \multicolumn{2}{|c|}{ Immediately } & \multicolumn{2}{|c|}{$2 \mathrm{~m}$ later } & \multicolumn{2}{|c|}{$3 m$ later } & \\
\hline Group & M & SD & M & SD & M & SD & \\
\hline Intervention & 40.12 & 20.12 & 42.10 & 21.88 & 48.34 & 22.02 & \\
\hline Control & 34.78 & 22.16 & 34.63 & 34.63 & 35.81 & 21.36 & \\
\hline
\end{tabular}

Table 4: Comparison of mean of Psychosocial Impacts score after the intervention in the two groups. diabetes leads to stress incontinence. Investigations in women with type 2 diabetes suggest that Physiological, microvascular and neurological complications of diabetes result in changes that may impair the function of continence mechanisms, including damage to the bladder innervation, altered detrusor muscle function or urothelial dysfunction [34].

Diabetes is also associated with reduced muscle strength, poor muscle quality, accelerated loss of lower extremity strength, and muscle mass contributing further to physical limitation. Urinary incontinence: could be the first manifestation of diabetes [35].

Evidence suggests that stress UI is due to dysfunction of the striated muscle of the urethral sphincter and pelvic floor muscles and their innervation. Research suggests that nearly $50 \%$ of severe incontinence could be avoided by preventing type 2 DM [36].

It is well documented that diabetes people with urinary incontinence have a lower Quality of Life (QoL) [37]. Ragins et al. [38] in their research reported that urinary incontinence is significantly associated with a decreased quality of life and those with more frequent incontinence have significantly lower quality of life scores. Aslan' study showed that, according to the results of the King Health Questionnaire, UI had a more unfavorable effect on women than on men [39]. Notably, incontinent individuals do not seek medical help because they either are not aware that effective treatments are possible, consider it as a natural aging process, or are too ashamed to mention it to their healthcare providers. The goal of healthy aging should not be only extending the life expectancy, but improving QOL [40].

During the past decade, a substantial body of evidence has been amassed to demonstrate that behavioral therapies, specifically pelvic muscle training and bladder training, should be prescribed before advancing to more invasive treatment [16].

Behavioral interventions are usually relatively inexpensive and easy to implement, but the effectiveness chiefly depends on the patient's adherence [6]. Obtaining women's trust and encouragement is essential if we are to provide early diagnosis and proper treatment [41].

The most recognized behavioral interventions for urinary incontinence are Pelvic Floor Muscle (PFM) exercise and bladder training. Both exercises are known to be effective in treating stress and urge incontinence [42]. Sampselle [16] conducted an interventional study on community-dwelling women. Pelvic muscle training was supplemented with bladder training for women with urge or mixed incontinence. After a 6 month observation period the treatment group experienced significant declines in the severity of UI and QOL were significantly improved in treatment versus control group.

In our study, the effect of a Behavioral Intervention Program on quality of life of the diabetes elderly females with urinary incontinence was examined in 60 females aged 60-74 years old referring to health Centers in Jahrom city. The results showed a considerable increase in I-QOL subtype scores, immediately, 2 and 3 months after the intervention for the subject's in the intervention group. According to Tables 2-4, immediately, 2 and 3 months after intervention, there was significant difference in I-QOL subtype scores, (the avoidance and limiting behavior $(\mathrm{P}=0 / 004)$, the psychological impact $(\mathrm{P}=0 / 05)$ and Social Embarrassment $(\mathrm{P}=0 / 04))$.

Forouhari et al. [43] did a study entitled "the Effects of training on quality of life in 62 menopause females". The results showed a 
significant increase in the mean scores in all quality of life dimensions (Vasomotor, psychological-social, physical, and sexual) in intervention group.

Our results support the Oh et al. [44], and Cardozo [45] studies that showed a significant improvement in the quality of life outcomes in elderly people with urinary incontinence. The results of all studies showed a significant improvement on the quality of life outcomes in elderly people with urinary incontinence.

\section{Conclusion}

Health care providers need to be sensitive to these deterrents and identify better ways to evaluate and discuses urinary incontinence (UI) with their patients. In addition, they can play an important role in teaching patients about their health condition, treatment options, and disease management. The Behavioral Intervention Program significantly improved the quality of life outcomes of the diabetic elderly females with urinary incontinence. Thus, it is concluded that the individuals with incontinence can be significantly improved following instruction by health care providers.

\section{Ethical Consideration}

- To perform the study, the researchers first attempted to obtain a referral and license from the School of Nursing and Midwifery in Jahrom city.

- Before starting the study, the subjects were presented with all the necessary basic information and adequate in relation to the objectives and process the work.

- At all stages of study were performed written consent of the subjects and they were assured that the information was confidential and only line of research analyzes.

- At the end of the study, a training booklet containing material discussed during the training sessions were given to the control group and health care centers.

\section{Suggestions for future research}

- The effect of training on quality of life of elderly middle-aged (84-75) with urinary incontinence

- The effect of training on quality of life of elderly diabetic(type 1) patients with urinary incontinence

- Comparison of the prevalence of urinary problems in elderly outpatients with those hospitalized

- Comparison of two methods of medication and behavioral techniques to reduce the signs and symptoms of urinary incontinence in elderly (Appendix 1).

\section{References}

1. Litwin MS, Saigal CS (2007) Urologic Diseases in America. Washington, DC: US Department of Health and Human Services, Public Health Service, National Institutes of Health. National Institute of Diabetes and Digestive and Kidney Diseases.

2. Drach G (2008) Fundamental issues in geriatric surgical care. American Urologic Association Plenary Session, Orlando, FL.

3. Bates F, Porter G (2003) The Role of the Nurse Incontinence Advisor in a Urology Wellness Clinic. A Publication of the Urology Nurses of Canada.

4. Abrams P, Cardozo L, Fall M, Griffiths D, Rosier P, et al. (2002) The standardization of terminology of lower urinary tract function: report from the standardization sub-committee of the International Continence Society. Neurourol Urodyn 21: 167-178

5. Brown JS (2002) Epidemiology and changing demographics of overactive bladder: a focus on the postmenopausal woman. Geriatrics 57 Suppl 1: 6-12.

6. Ko Y, Lin SJ, Salmon JW, Bron MS (2005) The impact of urinary incontinence on quality of life of the elderly. Am J Manag Care 11: S103-111.

7. Thom DH, Brown JS (1998) Reproductive and hormonal risk factors for urinary incontinence in later life: a review of the clinical and epidemiologic literature. Am Geriatr Soc 46: 1411-1417.

8. Shaw C (2001) A review of the psychosocial predictors of help-seeking behaviour and impact on quality of life in people with urinary incontinence. $J$ Clin Nurs 10: 15-24.

9. Matza LS, Zyczynski TM, Bavendam T (2004) A review of quality-of-life questionnaires for urinary incontinence and overactive bladder: which ones to use and why? Curr Urol Rep 5: 336-342.

10. Shaw C, Tansey R, Jackson C, Hyde C, Allan R (2001) Barriers to help seeking in people with urinary symptoms. Fam Pract 18: 48-52.

11. Margalith I, Gillon G, Gordon D (2004) Urinary incontinence in women under 65: quality of life, stress related to incontinence and patterns of seeking health care. Qual Life Res 13: 1381-1390.

12. Coyne KS, Sexton CC, Irwin DE, Kopp ZS, Kelleher CJ, et al. (2008) The impact of overactive bladder, incontinence and other lower urinary tract symptoms on quality of life, work productivity, sexuality and emotional well-being in men and women: results from the EPIC study. BJU Int 101: 1388-1395.

13. Stewart WF, Van Rooyen JB, Cundiff GW, Abrams P, Herzog AR, et al. (2003) Prevalence and burden of overactive bladder in the United States. World J Uro 20: 327-336.

14. Moore KN, Saltmarche B, Query A (2003) Urinary incontinence. Non-surgical management by family physicians. Can Fam Physician 49: 602-610

15. Ouslander JG, Griffiths PC, McConnell E, Riolo L, Kutner M, et al. (2005) Functional incidental training: a randomized, controlled, crossover trial in Veterans Affairs nursing homes. J Am Geriatr Soc 53: 1091-1100.

16. Sampselle CM (2003) Behavioral intervention: the first-line treatment for women with urinary incontinence. Curr Urol Rep 4: 356-361.

17. Marcell D, Ransel S, Schiau M, Duffy EG (2003) Treatment options alleviate female urge incontinence. Nurse Pract 28: 48-54.

18. Dickson MJ (2008) Nonsurgical treatment of stress urinary incontinence. BJOG 115: $1062-1063$

19. Kumari S, Jain V, Mandal AK, Singh A (2008) Behavioral therapy for urinary incontinence in India. Int J Gynaecol Obstet 103: 125-130.

20. Choi H, Palmer MH, Park J (2007) Meta-analysis of pelvic floor muscle training randomized controlled trials in incontinent women. Nurs Res 56: 226-234.

21. Hay-Smith EJ, Dumoulin C (2006) Pelvic floor muscle training versus no treatment, or inactive control treatments, for urinary incontinence in women. Cochrane Database Syst Rev 1: CD005654.

22. Jundt K, Peschers UM, Dimpfl T (2002) Long-term efficacy of pelvic floor reeducation with EMG-controlled biofeedback. Eur J Obstet Gynecol Reprod Biol 105: 181-185.

23. Bradley CS, Rovner ES, Morgan MA, Berlin M, Novi JM, et al. (2005) A new questionnaire for urinary incontinence diagnosis in women: development and testing. Am J Obstet Gynecol 192: 66-73.

24. Dougherty M, Bishop K, Mooney R, Gimotty P (1989) The effect of circumvaginal muscle (CVM) exercise. Nurs Res 38: 331-335.

25. Lee YS (1993) Effects of circum vaginal muscle exercise in stress incontinence women. Unpublished Doctoral Dissertation, Yonsei University, Seoul.

26. Hay-Smith EJ, Bø K, Berghmans LC, Hendriks HJ, de Bie RA, et al. (2007) Withdrawn: Pelvic floor muscle training for urinary incontinence in women. Cochrane Database Syst Rev: CD001407.

27. Tuomilehto J, Lindström J, Eriksson JG, Valle TT, Hämäläinen H, et al. (2001) Prevention of type 2 diabetes mellitus by changes in lifestyle among subjects with impaired glucose tolerance. N Engl J Med 344: 1343-1350.

28. Teunissen D, Van Den Bosch W, Van Weel C, Lagro-Janssen T (2006) "It can 
Citation: Jahromi MK, Ramezanli S, Taheri L, Rahmanian A (2014) Management of Stress Urinary Incontinence in Females with Diabetic Mellitus (Type 2). J Diabetes Metab 5: 351. doi:10.4172/2155-6156.1000351

Page 5 of 5

always happen": the impact of urinary incontinence on elderly men and women. Scand J Prim Health Care 24: 166-173.

29. Minassian VA, Drutz HP, Al-Badr A (2003) Urinary incontinence as a worldwide problem. Int J Gynaecol Obstet 82: 327-338.

30. Kuh D, Cardozo L, Hardy R (1999) Urinary incontinence in middle aged women: childhood enuresis and other lifetime risk factors in a British prospective cohort. J Epidemiol Community Health 53: 453-458.

31. Adeline M (1998) Urinary Incontinence in Individuals with Diabetes Mellitus. Diabetes Spectrum 11: 241-247.

32. Waetjen LE, Liao S, Johnson WO, Sampselle CM, Sternfield B, et al. (2007) Factors associated with prevalent and incident urinary incontinence in a cohort of midlife women: a longitudinal analysis of data: study of women's health across the nation. Am J Epidemiol 165: 309-318.

33. Lifford KL, Curhan GC, Hu FB, Barbieri RL, Grodstein F (2005) Type 2 diabetes mellitus and risk of developing urinary incontinence. J Am Geriatr Soc 53: 1851-1857.

34. Brown JS, Vittinghoff E, Lin F, Nyberg LM, Kusek JW, et al. (2006) Prevalence and risk factors for urinary incontinence in women with type 2 diabetes and impaired fasting glucose: findings from the National Health and Nutrition Examination Survey (NHANES) 2001-2002. Diabetes Care 29: 1307-1312.

35. Volpato S, Bianchi L, Lauretani F, Lauretani F, Bandinelli S, et al. (2012) Role of muscle mass and muscle quality in the association between diabetes and gait speed. Diabetes Care 35: 1672-1679.

36. Subak LL, Whitcomb E, Shen H, Saxton J, Vittinghoff E, et al. (2005) Weight loss: a novel and effective treatment for urinary incontinence. J Urol 174: 190-195.
37. Currie CJ, McEwan P, Poole CD, Odeyemi IA, Datta SN, et al. (2006) The impact of the overactive bladder on health-related utility and quality of life. BJU Int 97: 1267-1272.

38. Ragins Al, Shan J, Thom DH, Subak LL, Brown JS, et al. (2008) Effects of urinary incontinence, comorbidity and race on quality of life outcomes in women. J Urol 179: 651-655.

39. Aslan E, Beji NK, Erkan HA, Yalcin O, Gungor F (2009) Urinary incontinence (UI) and quality of life (QoL) of the elderly residing in residential homes in Turkey. Arch Gerontol Geriatr 49: 304-310.

40. Jackson RA, Vittinghoff E, Kanaya AM, Miles TP, Resnick HE, et al. (2004) Urinary incontinence in elderly women: findings from the Health, Aging, and Body Composition Study. Obstet Gynecol 104: 301-307.

41. Tunc TE (2008) Female urinary incontinence and the construction of nineteenthcentury stigmatized womanhood. Urology 71: 767-770.

42. Burgio KL (2004) Behavioral treatment options for urinary incontinence. Gastroenterology 126: S82-89.

43. Forouhari S, Khajehei M, Moattari M, Mohit M, Rad MS, et al. (2010) The Effect of Education and Awareness on the Quality-of-Life in Postmenopausal Women. Indian J Community Med 35: 109-114.

44. Oh HS, Kim MK, Seo WS (2005) Effectiveness of a behavioral intervention program for urinary incontinence in a community setting. Taehan Kanho Hakhoe Chi 35: 1476-1484.

45. Cardozo L (2004) New developments in the management of stress urinary incontinence. BJU Int 94 Suppl 1: 1-3. 